\title{
A IMPORTANCIA DA DANÇA NO DESENVOLVIMENTO PSICOMOTOR DE CRIANÇAS E ADOLESCENTES
}

Andrea Pedroni Falsarella

Danielle Bernardes-Amorim

\section{Resumo}

O ser humano possui múltiplas habilidades físicas, e a dança esta relacionada, através do movimento corporal, com o seu crescimento e desenvolvimento. Este artigo baseia- se na analise da aplicação de um trabalho, realizado com meninas entre seis e quatorze anos de idade, praticantes de aulas de dança. Pode verificar que a dança pode ser um importante aliado da Educação, no sentido que através dela a criança desenvolve simultaneamente aspectos motores, emocionais, e cognitivos. Aspectos esses que interagem e se completam.

\section{Palavras Chave}

Dança; Desenvolvimento psicomotor; Educação.

\section{THE IMPORTANCE OF THE DANCE IN DEVELOPMENT PSICOMOTOR OF CHILDREN AND ADOLESCENTS}

Andrea Pedroni Falsarella

Danielle Bernardes-Amorim

\begin{abstract}
The human being has multiple physical skills, and dancing is related, by means of body movement, to their growing. This article is based on the analysis of the application of a project carried out with six to fourteen year-old girls, who take dance classes, It was verified that dancing can be an important ally of education, in a sense that through it the child develops simultaneously motor, emotional and cognitive aspects. Aspects which interact and complete each other.
\end{abstract}

\section{Key-Words}

Dance; Psychomotor Development; Education. 


\section{INTRODUÇÃO}

Vários estudos mostram não apenas a maturação, mas também a quantidade e a qualidade de experiências motoras com o propósito de uma atuação mais significativa e objetiva sobre o movimento ou aprendizagem do movimento podendo levar o ser humano a apresentar uma serie de mudanças desenvolvimentistas (NANNI, 2001). O problema e que a noção de disciplina na escola sempre foi entendida como "não-movimento" e as crianças educadas e comportadas são aquelas que simplesmente não se move. Alias, professores e diretores Lançam mão da imobilidade física como punição e da liberdade de se movimentar como premio. Embora conscientes de que o corpo e o veiculo através do qual o individuo se expressa, o movimento corporal humano acaba ficando restrito a momentos precisos como as aulas de Educação Física e o horário do recreio. Nas demais atividades em sala, a criança deve permanecer sentada em sua cadeira, em silencio e olhando para frente (STRAZZACAPPA, 2001). Ainda, alguns julgam que, para ocorrer a aprendizagem, e preciso que o aluno esteja sempre sentado e quieto. Mas, privilegiar a mente e relegar o corpo pode levar a uma aprendizagem empobrecida (SCARPATO, 2001).

Alem disso, pelo alto valor atribuído a habilidade física em crianças e em adultos, o movimento serve como importante facilitador de um autoconceito positivo. Princípios saudáveis de crescimento e desenvolvimento devem ser adotados e seguidos para fornecer as crianças experiências orientadas para o êxito que minimizem o potencial de fracasso. Assim, devem-se empregar experiências motoras desenvolvimentistas apropriadas, que estejam dentro do nível de habilidade do individuo, estabelecendo objetivos razoáveis para um desempenho dentro dos limites de suas habilidades. Embora o movimento seja somente um caminho pelo qual um autoconceito positivo pode ser incentivado, devemos reconhecer que ele e importante para a maioria das crianças (GALLAHUE; OZMUN, 2001).

Neste sentido, a dança oferece um campo pedagógico altamente funcional recolocando o Homem a sua linha evolutiva. O homem se confronta com seus próprios impulsos e necessidades, carregados de conflitos e tensões, assim como suas intenções de relacionamentos. Dançando ele procura exteriorizar, exprimir e eliminar tenta se relaxar e organizar (WOSIEN, 2000).

A dança e muito mais do que a sua própria palavra inspira. Ela envolve musica, som, ritmo, movimento, prazer, harmonia, intelecto, conhecimento, descoberta, formação pessoal e, sobretudo Educação para a vida (VERDERI, 2000). 
Por ser uma atividade coletiva e lúdica, acredita-se que a dança seja um instrumento de facilitação nos relacionamentos interpessoais, no desenvolvimento da auto-estima, da autoconfiança e do senso de responsabilidade. Também proporciona benefícios físicos como: aumento da resistência corporal, estética, postura e flexibilidade; alem de contribuir para o equilíbrio emocional dentro de um desenvolvimento do individuo como um todo.

Assim, com a necessidade de se ter habitos saudáveis de vida, a dança tem sido considerada um meio de combater os danos causados pela vida moderna. Entretanto, existem poucos estudos específicos sobre a relação entre a atividade de dança e a saúde psicológica. Por este motivo, as pesquisas nessa área precisam ser intensificadas. Portanto este estudo fundamenta-se na busca de resultados teóricos e práticos que sustentem a posição de que a dança auxilia nos aspectos psicossociais, fortalecendo comportamentos adequados nos demais contextos da sociedade.

\section{OBJETIVO}

O objetivo desse estudo foi analisar a percepção de pais e mães de crianças e de adolescente sobre os efeitos da dança para o desenvolvimento psicomotor.

\section{METODOLOGIA}

Este estudo teve delineamento observacional, clinico, transversal e prospectivo, tendo sido desenvolvido de acordo com as Normas Éticas para pesquisa envolvendo seres humanos (Resolução 196/96 do Conselho Nacional de Saúde/MS). Para isto, o projeto de pesquisa referente a este estudo foi inicialmente encaminhado ao Comitê de Ética em Pesquisa (CEP) da Universidade do Vale do Sapucai - UNIVAS, tendo sua aprovação no início do ano de 2007.

Tendo sido aprovado o projeto pesquisa, foi encaminhado um Termo de Consentimento Livre e Esclarecido a cerca de 100 pais/mães de meninas praticantes de dança, entre 04 e 16 anos idade da cidade de Santa Rita do Sapucaí (MG). Assim, cientes de estarem participando volunetáriamente e de que não haveria nenhuma conseqüência pela não participação, alguns dos pais/mães das meninas praticantes de dança assinaram ao termo de consentimento. 
Apos todo este procedimento, concordaram em participar da pesquisa um total de 46 pais/mães, de meninas entre 06 e 14 anos de idade, que praticavam aulas dança a um tempo minimo de seis meses, conforme demonstra quadro abaixo.

Quadro 1 - Distribuição das meninas cujos pais foram entrevistados por idade

\begin{tabular}{cc}
\hline Idade (anos) & Meninas (n) \\
\hline Seis & 03 \\
Sete & 04 \\
Oito & 04 \\
Nove & 05 \\
Dez & 05 \\
Onze & 10 \\
Doze & 05 \\
Treze & 06 \\
Quatorze & 04 \\
\hline
\end{tabular}

Para a coleta dos dados, foi aplicado um questionário com trinta questões fechadas sobre o comportamento apresentado pelas filhas em contextos diversificados, apos o inicio das atividades em dança. Para cada questão, os pais respondiam se a criança melhorou naquele quesito e quanta melhorou. Na primeira parte do questionário os pais responderam apenas "sim" ou "não" ao quesito, que foi pontuado no sim. Assim, cada criança poderia atingir no maximo trinta pontos.

$\mathrm{Na}$ segunda parte relativa ao "quanta melhorou", os pais deram uma nota de 01 a 04 pontos para a intensidade da melhora (melhorou pouco $=1 \mathrm{pt}$; melhorou bem $=2 \mathrm{pts}$; melhorou bastante $=3$ pts; melhorou muito $=4$ pts). Como eram 30 perguntas, a pontuação máxima obtida poderia ser de 120 pontos e a mínima de 30 pontos. Finalmente, estas questões foram agrupadas em 4 aspectos: afetivo (afetividade, agressividade, alegria, atitude de impulsividade, controle da impulsividade, espontaneidade, expressividade, insegurança, medo e responsabilidade); cognitivo (aproveitamento em outras atividades, aproveitamento escolar, concentração, criatividade, organização e rapidez na aprendizagem de novos passos 
de dança); motor (coordenação motora, flexibilidade corporal, postura, noção de espaço-temporal, noção de localização e ritmo musical) e social (atitude de cooperação, dificuldade de se enturmar, dificuldade em obedecer regras, equilíbrio emocional, falta de respeito com relação a outra pessoa, liderança, relação interpessoal e facilidade nas atividades em grupo).

Tendo subdivisão dos 04 aspectos em pontos e a subdivisão de faixas etárias comumente trabalhadas em aulas de dança ( $1^{\circ}$ grupo: 6-8 anos; $2^{\circ}$ grupo: $9-11$ anos; $3^{\circ}$ grupo: $\left.12-14\right)$ foi possível realizar-se a analise de variância (ANOVA One-way) e teste Post Hoc (Tukey-Kramer) para localização das diferenças, sendo considerado nível de significância de 0,05 . Alem disso, com todos os dados obtidos, realizou-se analise de correlação de Pearson entre idade das meninas e pontuação obtida no questionário respondido pelos pais/mães.

\section{RESULTADOS}

$\mathrm{Na}$ Figura 1, observa-se que dos 46 pais/mães questionados, 33\% mencionaram que suas filhas obtiveram melhora em todos os aspectos ( 30 pontos) e, 39\%, em quase todos os aspectos ( 25 a 29 pontos), somando a maioria dos pais/mães. Porem, o valor de correlação entre idade da menina e pontuação obtida no questionário respondido pelo pai/mãe foi de 0,11 , demonstrado não haver correlação do índice de melhora percebido pelo pai/mãe com a idade da filha. Alem disso, o teste de comparação de Tukey-Kramer para pontuação nos 3 grupos de faixa etária apresentou valor de $\mathrm{P}$ de 0,1114 , sendo portanto, considerada não significante a variação da pontuação entre as faixas etárias das meninas.

Para confirmar os dados anteriores, na Figura 2 observa-se a distribuição percentual de pontuação obtida no questionário por idade, em que se verifica distribuição similar ente todas as idades.

Com relação a segunda parte do questionário, em os pais respondiam "quanta melhorou" em cada aspecto podendo atingir um mínimo de 30 e maximo de 120 pontos, verificou-se que a variação ficou entre 32 e 112 pontos no presente estudo. Mas a divisão deste resultado em percentis apresentou 4 grupos: $1^{\circ}$ grupo com pontuação acima do percentil 85 (acima de 101 pontos); $2^{\circ}$ grupo com pontuação abaixo do percentil 85 mas acima do percentil 50 (entre 82 e 99 pontos); $3^{\circ}$ grupo com pontuação abaixo do percentil 50 mas acima do percentil 15 (entre 54 e 51 pontos); $4^{\circ}$ grupo com pontuação abaixo do percentil 15 (abaixo de 53 pontos). 


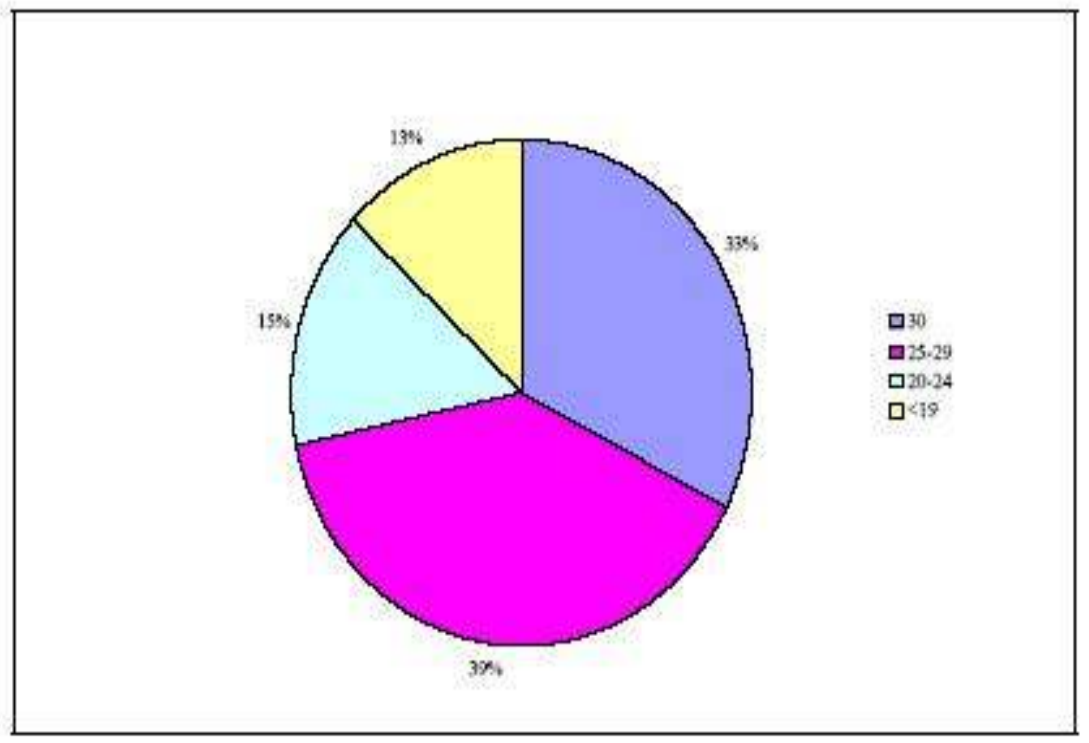

FIGURA 1 - Distribuição percentual de pontuação obtida no questionário

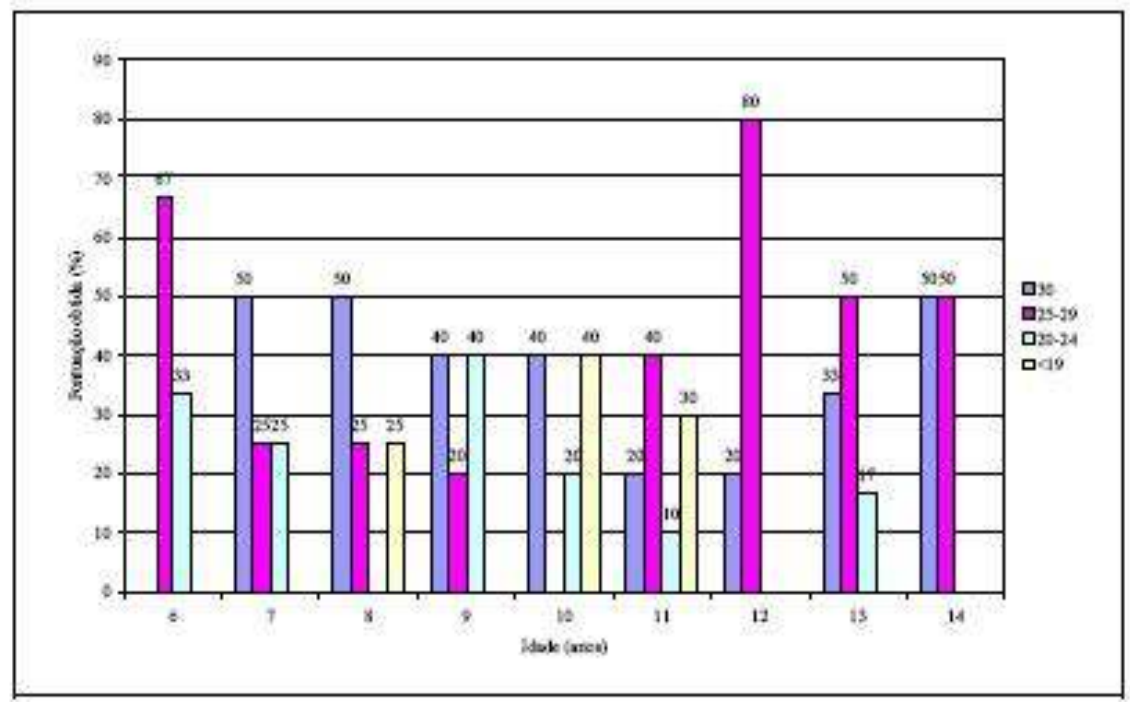

FIGURA 2 - Distribuição percentual de pontuação obtida no questionário por idade

A Figura 3 apresenta os resultados das porcentagens de pais/mães que obtiveram pontuação em cada percentil, demonstrando mais uma vez que a maioria dos pais respondeu para a maior pontuação. Porem, mais uma vez não houve correlação do índice de melhora percebido pelo pai/mãe com a idade da filha, pois o valor de $\mathrm{r}$ foi de 0,14 assim como o valor de $\mathrm{P}$ para comparação nos 3 grupos de faixa etária foi de 0,4289 . 


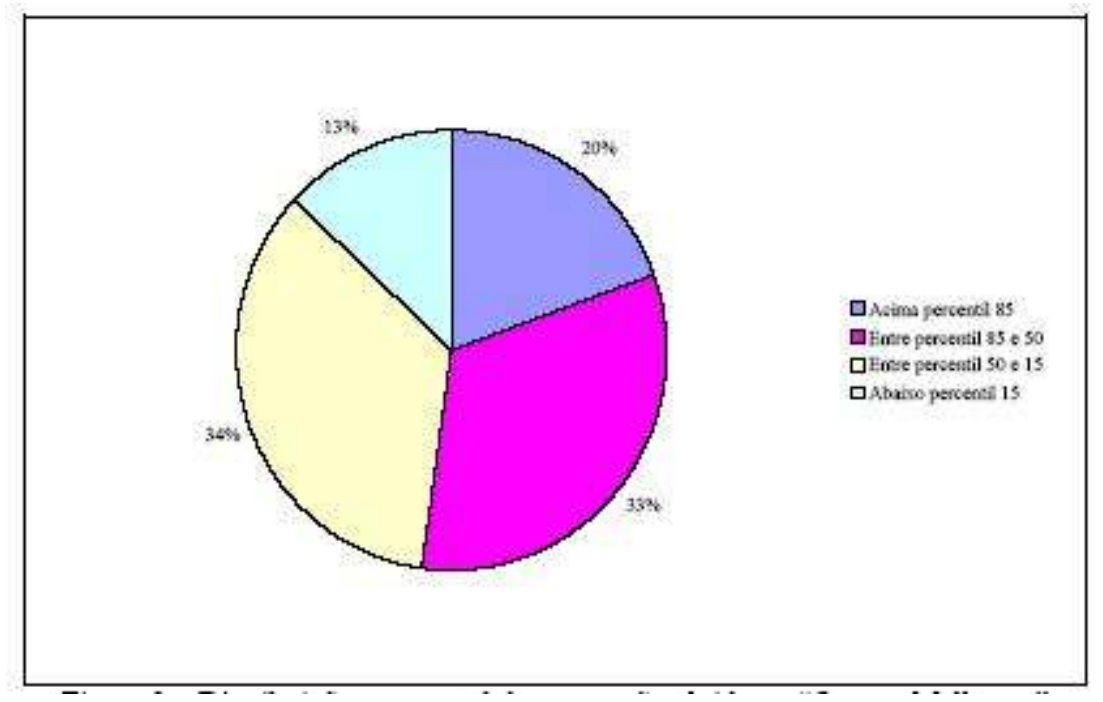

FIGURA 3 - Distribuição percentual de pontuação obtida no "Quanto Melhorou"

Na Figura 4 podemos observar a distribuição percentual obtida pelo questionário, que verificou: A maior percepção de melhora ficou para a faixa etária dos 11 anos, com 91\%. A menor percepção ficou para a faixa etária de 14 anos, com $29 \%$. E as outras faixas etárias restantes, ficaram com media em torno dos $50 \%$.

Finalmente, os trinta quesitos foram separados em 4 grandes aspectos: afetivo, social, cognitivo e motor. Com a soma de todos os quesitos calculou-se a media de pontuação no "quanta melhorou" por aspecto para cada criança. Por exemplo, uma criança cujo pai pontuou os quesitos do aspecto Afetivo com: Afetividade $=3 ;$ Agressividade $=4 ;$ Alegria $=3 ;$ Atitude de impulsividade $=4$; Controle da impulsividade $=4$; Espontaneidade $=4$; Expressividade $=4$; Insegurança $=4$; Medo $=4$; Responsabilidade $=4$; obteve media de pontuação no aspecto Afetivo de 3,8 pontos. 


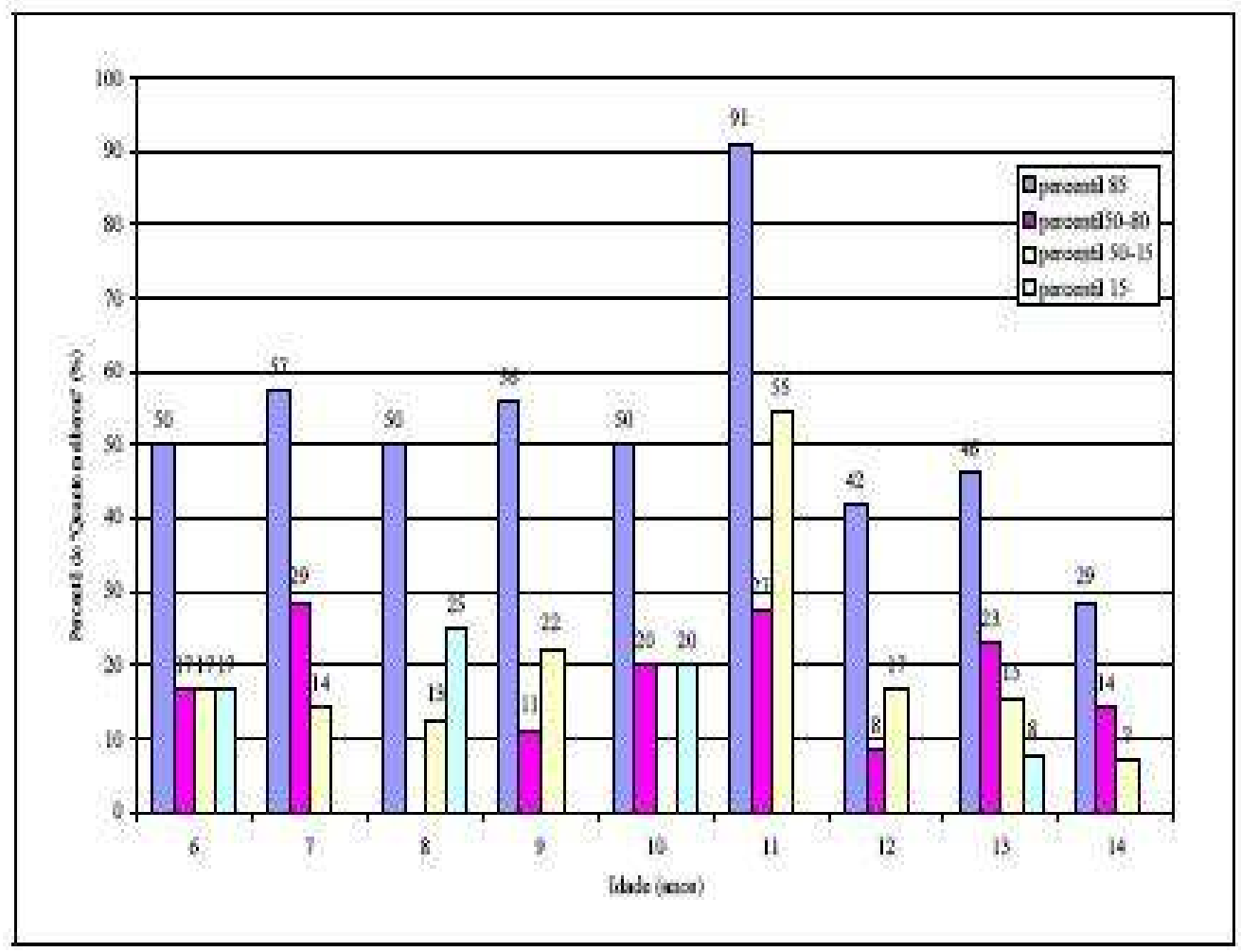

FIGURA 4 - Distribuição percentual do percentil de pontuação obtida no questionário por idade

Em seguida, calculou-se a media do aspecto para cada grupo de idade. Por exemplo, no grupo 7 anos, os pais/mães das quatro meninas, pontuaram respectivamente, 2,2;1,8;2,3 e 3,8 para o aspecto afetivo, resultando numa media de 2,5 pontos para a idade de 7 anos no aspecto Afetivo. Como a pontuação máxima seria de 4 pontos (caso todos os pais, pontuassem em 4 - melhorou muito - todos os aspectos), este valor representa uma melhora de 63\%. Com todas 4 as porcentagens (dos 4 aspectos) para cada idade, foi possível a confecção do gráfico da figura 5 que apresenta as porcentagens de melhora para cada idade em cada aspecto.

Neste gráfico, percebe-se que o aspecto afetivo esteve sempre em menor porcentagem para todas as faixas etárias e o teste de comparação de Tukey-Kramer apresentou valor de $\mathrm{P}<0,05$ para comparação entre os aspectos Afetivo e Social. Porem, não houve diferença entre os outros aspectos analisados.

\section{DISCUSSÃO}

A literatura considera as atividades que utilizam musica e movimento como motivantes, prazerosas e de grande importância para o desenvolvimento da criança e do adolescente, pois a percepção proprioceptiva 
depende de gestos de grande amplitude e de deslocamento do corpo inteiro. Deve estar sistematicamente associada ao máximo as percepções exteroceptivas: visuais, táteis e auditivas (TIBEAU, 2006).

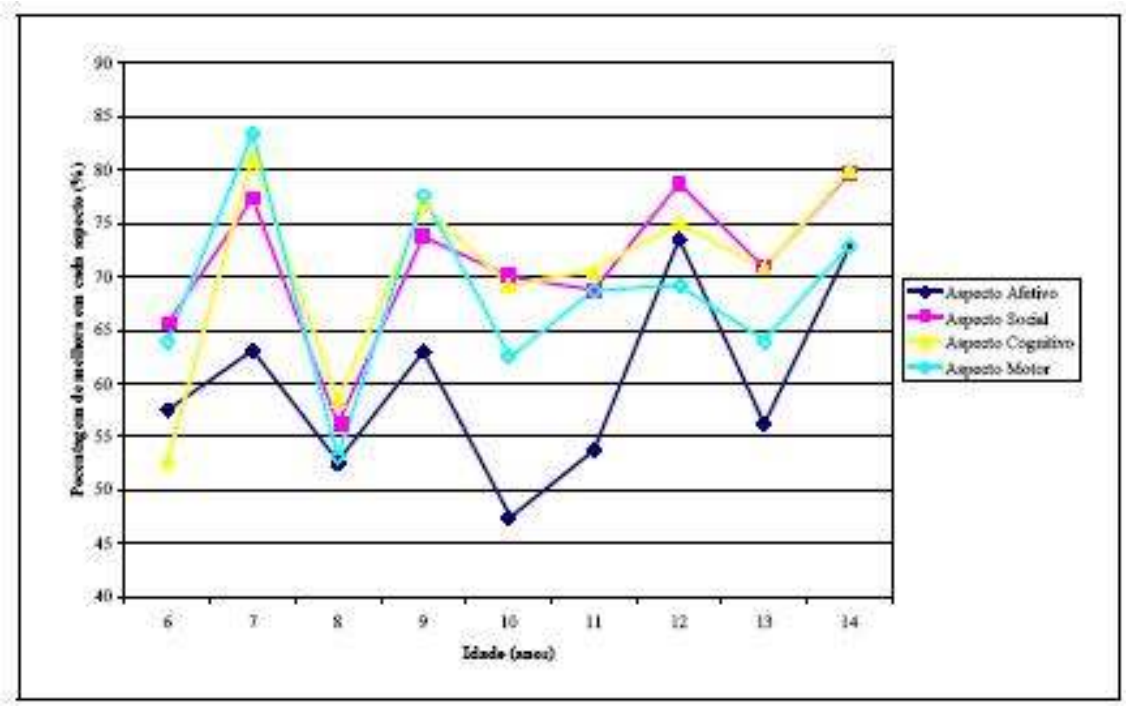

FIGURA 5 - Porcentagem de melhora em cada um dos aspectos analisados

Alias, o que se chama correntemente de um "gesto coordenado" e na realidade um gesto rítmico, isto e, uma boa estruturação temporal, conferindo-lhe certa harmonia. E através do ritmo dos movimentos registrados no seu corpo que a criança tem acesso a organização temporal. A percepção temporal permite, alem da consciência e da interiorização dos ritmos motores corporais, a percepção dos ritmos exteriores. Esta passagem constitui um estado indispensável para que a criança possa em seguida, tomar conta de seus próprios movimentos e organiza-los a partir da representação mental. Esta ultima possibilidade só se realizara no estagio seguinte do desenvolvimento psicomotor (LE BOULCH, 1982).

Os Parâmetros Curriculares Nacionais (BRASIL, 1997), que definem as atividades rítmicas como manifestações da cultura corporal com características de expressão e comunicação de gestos e a presença de musica, também colocam estes como conteúdos apropriados para a aquisição de capacidades motoras, cognitivas e socio-afetivas.

Quanta a isto, a cognição e o afeto são dois aspectos indissociáveis de uma mesma ação, e ambos seguem a mesma direção no processo de desenvolvimento. A afetividade constitui a energética da ação, ou seja, o interesse e a vontade que funcionam como reguladores da energia a qual impulsiona a conduta, e as estruturas de que a criança dispõe para agir correspondem as funções cognitivas (FREITAS; ASSIS, 2007). 
Ainda, embora os levantamentos da literatura concluam que existe somente uma ligeira relação entre desempenho intelectual e motor, professores de Educação Física, durante suas observações de crianças, tendem intuitivamente a hipotetizar sobre a existência de uma relação entre desenvolvimento mental e motor que reflete a natureza unitária do individuo (ECKERT, 1993).

Tais considerações reforçam a idéia de que a criança não e ora razão, ora emoção, como bem menciona o neurologista Damásio (1998) em sua obra "O erro de Descartes".

No presente estudo, observou-se que houve menor percepção de melhora no aspecto Afetivo em relação ao Social pelos pais das meninas de 06 a 14 anos que praticavam dança a pelo menos seis meses. Porem as considerações aqui levantadas colocam este resultado em discussão, uma vez que não se pode pensar a criança em partes: uma hora aspecto Afetivo, outra, Social.

Alguns pais mencionaram, no momenta de responder ao questionário, que suas filhas nunca apresentaram alguns dos quesitos negativos relativos ao Aspecto Afetivo, tais como Agressividade; Atitude de impulsividade; Controle da impulsividade; Insegurança e Medo. Assim, não marcaram estas alternativas com pontuação de melhora e, talvez este seja o motivo da diferença significativa observada no resultado final.

De qualquer forma, podemos perceber prelos resultados do estudo, sobretudo nas figuras 1,3 e 5 , que os pais possuem boa percepção acerca dos benefícios psicomotores da dança.

\section{CONCLUSÃO}

Através desse estudo, pode-se notar que os pais de crianças e adolescentes que dançam aceitam a modalidade como fator de melhora nos aspectos Afetivo, Social, Cognitivo e Motor. A diferença significativa observada entre aspectos Afetivo e social, com detrimento do aspecto afetivo, foi devido a interpretação do instrumento. Assim, novos estudos devem realizados, talvez com modificação no modo de questionamento realizado.

De qualquer forma, não podemos desconsidera que as aulas de dança, envolvem seus participantes, fazendo com que busquem novas possibilidades de movimentos, dando- lhes respaldo para essas novas experiências, e assim, vão tomando conhecimento de seu próprio corpo, de seus limites, trocando informações com colegas, solucionando problemas, gerando conhecimento. 


\section{REFERENCIAS}

ECKERT, Helen M. Desenvolvimento motor. 3. ed. São Paulo: Manole, 1993.

FREITAS, M. L. L. U.; ASSIS, O. Z. M. Os aspectos cognitivo e afetivo da criança avaliados por meio das manifestações da função simbólica. Ciências \& Cognição, v. 4, v. 11, p. 91-109, 2007. Disponível em http://www.cienciasecognicao.org.

GAllahUE, D. L.; OZMUN, J. C. Compreendendo o desenvolvimento motor: bebes, crianças, adolescentes e adultos. São Paulo: Phorte, 2001.

LE BOULCH, J. O desenvolvimento psicomotor: do nascimento aos 6 anos. 7 ed. Porto Alegre: Artmed, 1982.

NANNI, D. Dança educação: da pré-escola a universidade. 3 ed. Rio de Janeiro: Sprint, 2001.

SCARPATO, M. T. Dança educativa: um fato em escolas de São Paulo. Caderno CEDES, v. 21, n. 53, p. 57-68, abr. 2001.

STRAZZACAPPA, M. A Educação e a fabrica do corpo: a dança na escola. Caderno CEDES, v. 21, n. 53, p.69-83, abr. 2001.

TIBEAU, C. C. P. M. Motricidade e musica: aspectos relevantes das atividades rítmicas como conteúdo da Educação Física. Revista Brasileira de Educação Física, Esporte, Lazer e Dança, v. 1, n. 2, p. 53-62, jun. 2006.

VERDERI, E. B. L. P. Dança na escola. 2. ed. Rio de Janeiro: Sprint. 2000.

WOSIEN, B. Dança: um caminho para a totalidade. São Paulo: Trion, 2000. 


\section{Andrea Pedroni Falsarella}

Universidade do Vale do Sapucai - UNIVAS

\section{Danielle Bernardes-Amorim}

\section{Universidade do Vale do Rio Verde - UNINCOR}

\section{Referência do artigo:}

\section{ABNT}

FALSARELLA, A. P., AMORIM, D. B. A importância da dança no desenvolvimento psicomotor de crianças e adolescentes. Conexões, v. 6, p. 306-317, 2008.

\section{APA}

Falsarella, A. P., \& Amorim, D. B. (2008). A importância da dança no desenvolvimento psicomotor de crianças e adolescentes. Conexões, 6, 306-317.

\section{VANCOUVER}

Falsarella AP, Amorim DB. A importância da dança no desenvolvimento psicomotor de crianças e adolescentes. Conexões, 2008; 6: 306-317. 